\title{
Hydrodynamic performance and appendage considerations of wave-piercing planing craft overlapping waves and porpoising
}

\author{
Sangwon KIM*, Nobuyuki OSHIMA*, Sangeui LEE**, Gyoungwoo LEE*** and Kwangcheol SEO*** \\ *Department of Mechanical and Space Engineering, Hokkaido university \\ Kita-13, Nishi-8, Kita-ku, Sapporo, Hokkaido 060-8628, Japan \\ E-mail: swkim5834@eis.hokudai.ac.jp \\ **Department of Mechatronics Convergence, Changwon National University \\ 20 Changwondaehak-ro, Uichang-gu, Changwon, Gyeongsangnam-do, 51140 Korea \\ ${ }^{* * *}$ Department of Naval Architecture \& Ocean Engineering, Mokpo National Maritime University \\ 91, Haeyangdaehak -ro, Mokpo, Jeollanam-do, 58628, Korea
}

Received: 7 December 2019; Revised: 25 December 2019; Accepted: 14 January 2020

\begin{abstract}
This work addresses the numerical study of wave-piercing planing hull and related hydrodynamic performance as the appendages. From the half century ago, the interest in high-speed planing crafts has been advanced toward maintaining performance stably. The main reasons to make it hard are instability motion occurring from porpoising and wave condition. Porpoising is mainly due to overlap the heaving and pitching motion with certain period, which is caused by instable pressure distribution and changing longitudinal location of center of gravity. In addition, in wave condition, encountering wave disturbs going into planing mode. This paper presents numerical results of wave-piercing planing hull in porpoising and wave condition. Numerical simulation is conducted via Reynolds Averaged Navier-stokes (RANS) with moving mesh techniques (overset grid), performed at different wave condition. The numerical results reveal motion characteristics overlapping porpoising and wave condition. At first, motions on low wavelength region show resonance on this condition, and some appendages enhance the motion amplitude larger than original values. Finally, this resonance was suppressed by stern appendages. However, momentum generated from stern appendages increases motions in high wavelength region. This effective motion corresponds with vertical accelerations from CG.
\end{abstract}

Keywords : Porpoising, Seakeeping performance, Ship hydrodynamics, Wave-piercing planing hull

\section{Introduction}

High-speed planing craft shows high propulsion efficiency compared to the same class of displacement ship, and naval architects has used it for various purposes. However, not only can these characteristics quickly disappear but also slamming and structure damage can occur due to internal and external factors. One, which mentioned as external factor, is waves. This topic has been widely studied to understand planing craft behavior and characteristic.

It started from Fridsma (1969), which conducted model tests on regular waves on prismatic planing hull-forms to define the effects of parameters such as deadrise, loading, length-beam ratio and so on. Then, Fridsma (1971) examined the ship motion with same vessels on irregular waves (i.e. sea states). Based on Fridsma (1971), Zarnick and Turner (1981) conducted irregular wave experiments on a high L/B ratio prismatic planing hull-forms and reported that the performances was good in calm water but deteriorated in waves. In addition, Savitsky and Ward Brown (1976) reviewed Fridsma's research (1971) and disclosed some relationship as the factors discussed below.

First, resistance-induced wave had a nonlinear relationship with the speed while showing a linear relationship with the vertical acceleration. Furthermore, it was confirmed that all the performance deteriorated as the wave increased. The increase in deadrise was favorable among waves and attenuates additional resistance, but more power was required to secure the thrust. Trim reduction is advantageous for vertical acceleration and motion, while the additional resistance increases. The increase in weight is advantageous in reducing the vertical acceleration, the motion, and the additional 
resistance. The increase in length-beam ratio results in an increment of the vertical acceleration and motion at high speeds.

Then, Savitsky and Koebel (1993) reported the design elements such as the hull section and parameters, the location and shape of appendages to improve the seakeeping performance at certain sea state such as beam, quartering and following encounter. Begovic et al. (2014) conducted experimental work with regular waves with a series of non-uniform deadrise planing hull-forms to evaluate the effects of deadrise angle variation along the hull length on seakeeping characteristics and to provide a benchmark for the CFD of a planing hull.

To extend Begovic et al. (2014), Begovic et al. (2016) undertook an experimental assessment of seakeeping performance in irregular head waves. It emphasized statistical analysis and best-fit distribution of planing hull motions and accelerations in an irregular head sea. An internal factor affected by performance of planing craft, is instability motion. One typical instability motion in a planing craft is porpoising, which generates combined oscillations of pitch and heave motions even when there are no waves. It could be sustained or increased while in planing condition. In 1930, these studies started predicting the porpoising of water-based aircraft like floating seaplanes or flying boat in Fig. 1, when would occur during takeoff with a sea runaway. Sottorf (1949) reported systematic model tests on the stability limits of a series of floating seaplanes. Kenneth and Locke, Jr. (1943) conducted experimental studies into porpoising limits for flying-boat hull. Based on this research, Locke. Jr. (1943) presented the results of a general porpoising test of the same model for comparison. Thanks to both experimental works, porpoising limits could be easily predicted.

For planing craft, Benson and Lina (1942) investigated the effect of the deadrise angle of the V-bottom planing surface upon low-angle-type porpoising. They confirmed that the increasing deadrise angle at $10^{\circ}-30^{\circ}$ lead to important increases in the lower limit of stability. Day and Haag (1952) undertook a systematic series of tests of constant deadrise prismatic planing surfaces to determine the porpoising limits for planing hull-forms to provide boat designers with useful data on the inception of porpoising in terms of trim angle, speed, weight and deadrise. Savitsky (1964) reviewed Locke Jr. (1943) and Day and Haag (1952). In this review, the porpoising limits were not dependent upon the pitch moment of inertia. Its effects on the changes in the frequency of oscillatory motion were of increasing frequency for small pitch inertia value. Katayama (2004) established the mechanism of porpoising by self-excited oscillation. When starting one of the motions caused by some disturbance, this motion (i. e. heave and pitch motion) causes the opposite motion's restoring moment or force to occur simultaneously. Then, the opposite motion causes the same phenomenon alternately. In this time, the phase difference for proper occurrence is $\pi / 2$. Thus, porpoising is usually avoided in design stage by moving the LCG position to forward or attaching appendages to the reduce trim angle. However, there are cases in which porpoising occurs due to modifications such as changing the purpose or requirements of fishing boat and special-purpose vessels. This paper presents research motion characteristics of wave-piercing planing craft under overlapped conditions both waves and porpoising. On the hull-form, the wave-piercing planing hull, which will refer to in section 2, was used, and this hull-form has the characteristic that the porpoising occurs after a specified speed. The performance of planing crafts is evaluated by commercial CFD code, STAR-CCM+. The SST k- $\omega$ turbulent model which is one of the RANS models was used along with the Volume of Fluid (VOF) method to describe the water and air around the hull.

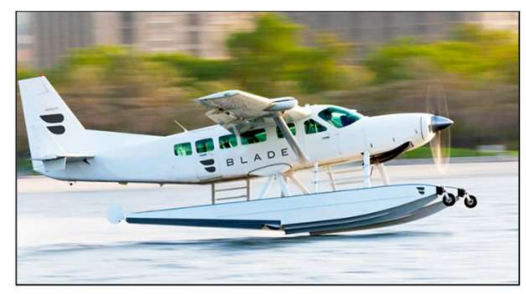

Seaplane<Blade Co.>

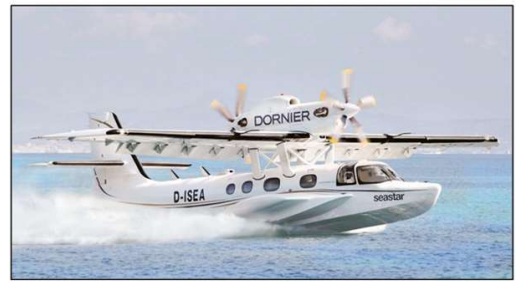

Flying boat $<$ Dornier Seawings Co.>

Fig. 1 Seaplane and flying boat
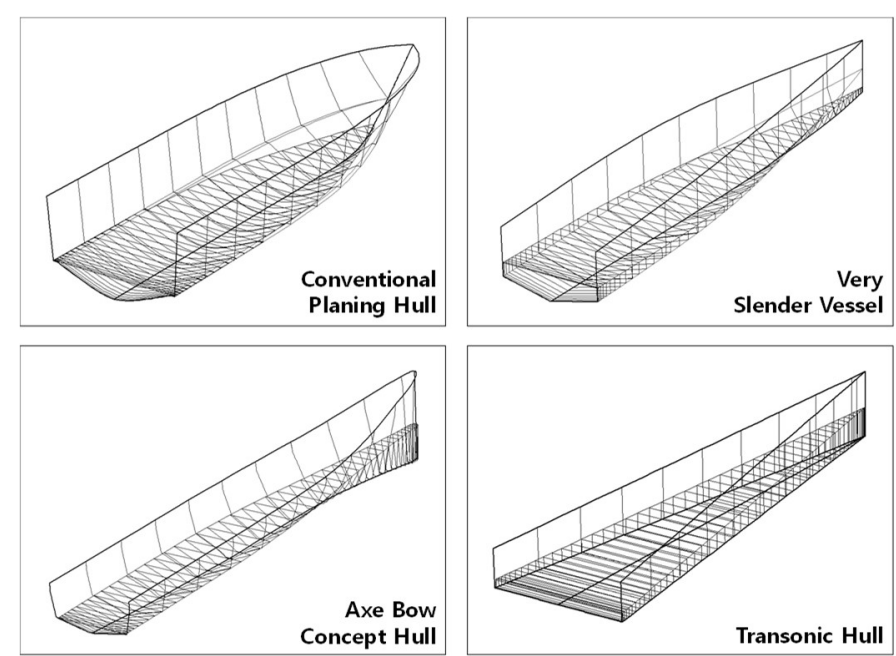

Fig. 2 Conceptual geometries as hull-concepts [20] 


\begin{tabular}{|llll|}
\hline NOMENCLATURE & & \\
$\mathrm{A}$ & wave amplitude, $\mathrm{m}$ & $U_{i}$ & \\
$B$ & breath, $\mathrm{m}$ & $U_{j}$ & velocity in $i$ dimension, $\mathrm{m} / \mathrm{s}$ \\
$B_{S}$ & breath of appendage, $\mathrm{m}$ & $U$ & velocity in $j$ dimension, $\mathrm{m} / \mathrm{s}$ \\
$F r_{V}$ & volume froude number & $w$ & velocity of boat, $\mathrm{m} / \mathrm{s}$ \\
$f$ & frequency, $1 / \mathrm{s}$ & $x_{i}$ & wave frequency, $\mathrm{rad} / \mathrm{s}$ \\
$g$ & gravitational acceleration, $9.80665 \mathrm{~m} / \mathrm{s}^{2}$ & $x_{j}$ & spatial coordinate in $i$ dimension, $\mathrm{m}$ \\
$\mathrm{H}$ & wave elevation, $\mathrm{m}$ & $y^{+}$ & dimensionless wall distance \\
$\mathrm{H} / \lambda$ & wave steepness & $\nabla$ & Displacement volume, $\mathrm{m}^{3}$ \\
$k$ & turbulent kinetic energy, $\mathrm{m} / \mathrm{s}$ & $\alpha_{C G}$ & vertical acceleration at CG, $\mathrm{m} / \mathrm{s}^{2}$ \\
$\mathrm{~K}$ & wave number, rad $/ \mathrm{m}, \mathrm{K}=2 \pi / \lambda$ & $\beta$ & deadrise angle, angle of appendage, deg \\
$\mathrm{LOA}$ & length over all of hull, $\mathrm{m}$ & $\eta_{3}$ & heave displacement, $\mathrm{m}$ \\
$\mathrm{LS}$ & length of appendage, $\mathrm{m}$ & $\eta_{5}$ & pitch displacement, deg \\
$\mathrm{LCG}$ & longitudinal CG from transom, $\mathrm{m}$ & $\lambda$ & wave-length, $\mathrm{m}$ \\
$\mathrm{VCG}$ & vertical CG from bottom, $\mathrm{m}$ & $\lambda / \mathrm{LOA}$ & wave-length to LoA of hull ratio \\
$m$ & mass, $\mathrm{kg}$ & $v$ & kinematic viscosity, $\mathrm{m}^{2} / \mathrm{s}$ \\
$P$ & pressure, Pa & $\rho$ & density of fluid, $\mathrm{kg} / \mathrm{m}^{3}$ \\
$t$ & time, $\mathrm{s}$ & $\omega$ & specific dissipation rate \\
$\mathrm{T}$ & draft, $\mathrm{m}$ & & \\
& & & \\
\hline
\end{tabular}

\section{Models Characteristics}

The research that deals with the seakeeping performance of planing crafts can be divided into two groups. The first group derives elements or knowledge that improve seakeeping performance or seeks to understand the characteristics for further research as referenced in the introduction. The second group introduces new concept hull-forms based on previous research like the following studies. There are three kinds of concept that are milestones in the seakeeping performance of planing hull-form as shown Fig. 2.

The first concept is Very Slender Vessel (VSV) (1997) and is a more conventional concept than any other. VSV adopts an extreme deadrise angle, and it looks like a wedge that can break through bow waves at high speed, and the stern shape is like that of a planing hull to perform the same function as a planing hull.

The second concept, the Enlarged Ship Concept (ESC), was presented by Keuning and Pinkster (1995), and this concept was based on increasing the length of the bow section $25-50 \%$ while most parameters such as the beam, depth, and deadweight were secured as much as possible. There were considerable improvements in the resistance and seakeeping performance. After this, J.A. Keuning et al. (2001) conducted experiments to improve the seakeeping performance and maneuvering characteristic of ESC on the head and following irregular waves to investigate the sensitivity of broaching in following waves. Based on ESC, Axe Bow Concept (ABC) was presented by Keuning et al. (2002) with the aim of reducing the wave impact forces and the hydrodynamic lift in the forward of the ship. It was very slender and deeper like the axe blade forward end part of the hull.
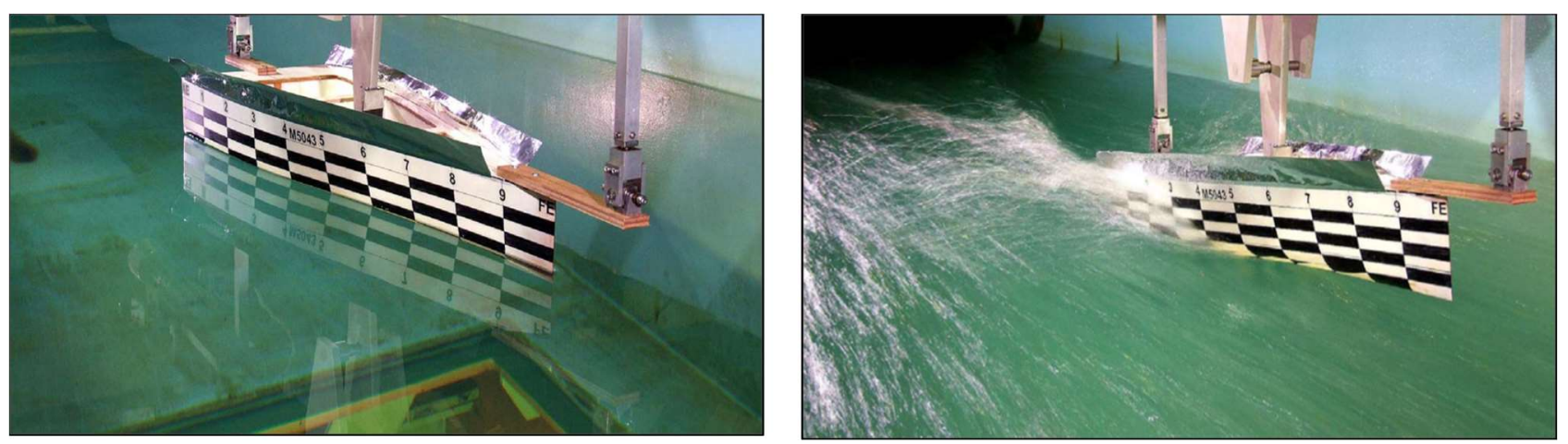

Fig. 3 Experimental set up of WPPH 
The last one is Transonic hull (TH), as presented by Calderon and Hedd (2011). It has a slender triangular hull-form with an apex-forward design and minimum depth at the stern to eliminate the principal cause of residual resistance. It has demonstrated reduced residual resistance and an increment of $17 \%$ speed at equal power in calm and regular wave conditions, but the TH concept is currently in the development stage. The wedge-shape of bow is a common characteristic of hulls mentioned above. In addition, Wave-Piercing Planing Hull-form (WPPH), which is the target hull-form in this paper, embodies the same wedge-shape at bow. The initial hull-form was initiated by Jeong et al. (2016) and they conducted model tests as shown in Fig. 3.

The main finding was that the spray extended from the side to the stern of the vessel, and a series of side appendages were evaluated to suppress the spray. Then, Kim et al. (2017a) offered a numerical simulation to estimate the hydrodynamic of modified hull-form, which is the same model as in this study, compared to the initial hull-form. Kim et al. (2017a) points out that the porpoising of the modified model was starting from $F r_{V}=3.95$, where the $F r_{V}$ is defined as:

$$
F r_{V}=U / \sqrt{g \cdot \nabla^{1 / 3}}
$$

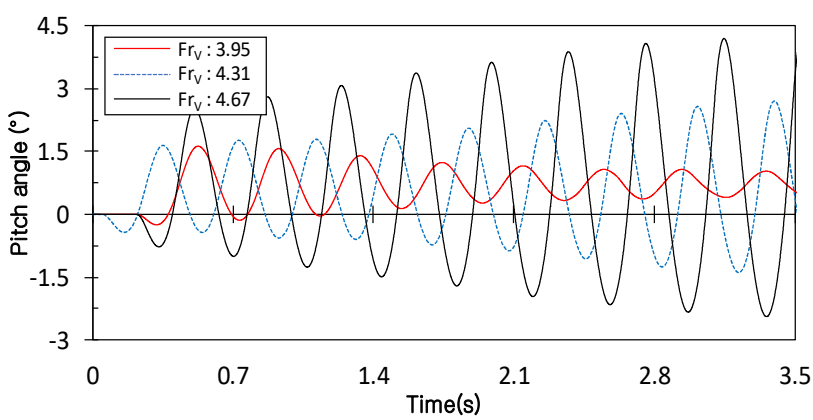

Fig. 4 Porpoising on pitch motion (Kim et al., 2017a)

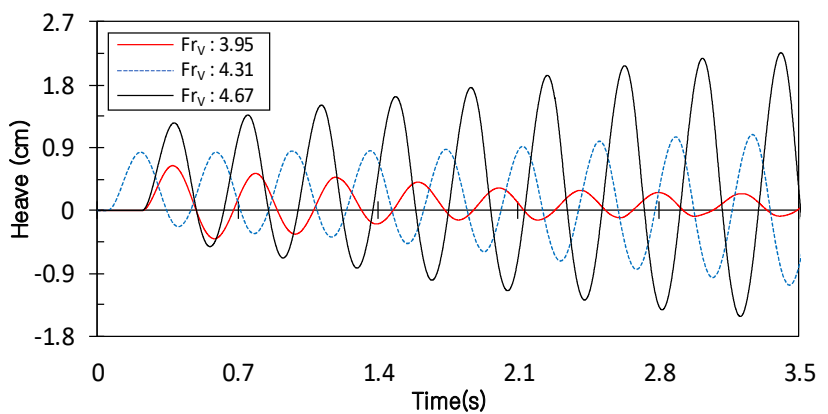

Fig. 5 Porpoising on heave motion (Kim et al., 2017a)

In addition, porpoising significantly increased in proportion with $F r_{v}$, as shown in Figs. 4-5. First, numerical simulations were conducted with spray rails, which were applied in Jeong et al (2016) and shown in Fig. 6 (left). However, suppressing spray suddenly emerged as a problem for the following reason: although existing appendages (spray railtype) could suppress the spray at constant running attitude, the starting point of the spray moved back and forward when porpoising, which periodically spreads spray over the appendages. Thus, it reduced the performance and comfort level on the boat. To overcome this situation, a hard-chine concept like Fig. 6 (left) was implemented. Therefore, not only was porpoising suppressed by 33-55\%, but also spray could be totally blocked. Then, Kim et al. (2017b) conducted a numerical analysis of the stern appendages and suppressed porpoising completely at the design speed range. In this study, the side and stern appendages were selected like Fig. 6.

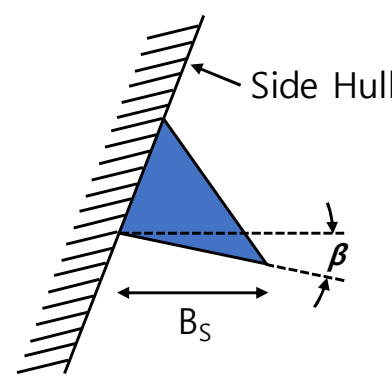

-Spray rail-

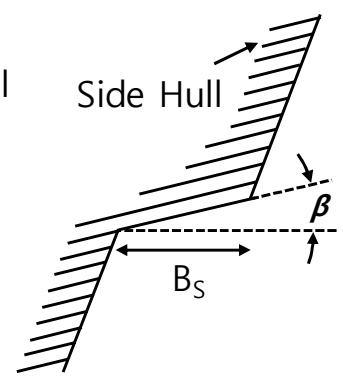

-Hard chine-

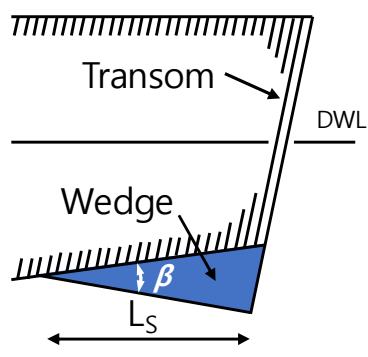

※WL : Design Water Line

-Trim Wedge-

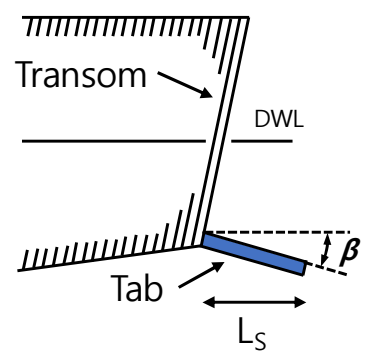

-Trim Tab-

Fig. 6 Description of appendages / (left) side, (right) stern 


\section{Numerical Simulation Setup}

\subsection{Governing Equations}

The governing equations adopted in this study are continuity and Navier-Stokes equations for incompressible, unsteady and viscosity fluid with the gravitational acceleration as shown in Eq. (2). These equations are changed into Reynolds-Averaged Navier-Stokes (RANS) by Reynolds decomposition on velocity and pressure as Eq. (3). Finally, RANS equations are written as Eq. (4) with including reynolds stress tensor, $\overline{u_{\imath} u_{\jmath}}$.

$$
\begin{aligned}
& \frac{\partial U_{i}}{\partial x_{i}}=0, \frac{\partial U_{i}}{\partial t}+U_{j}=-\frac{1}{\rho} \frac{\partial P}{\partial x_{i}}+v \frac{\partial^{2} U_{i}}{\partial x_{j} \partial x_{j}}+g_{i} \\
& U_{i}=\overline{U_{i}}+u_{i}, P=\bar{P}+p \\
& \frac{\partial \overline{U_{i}}}{\partial x_{i}}=0, \frac{\partial \overline{U_{i}}}{\partial t}+\overline{U_{j}} \frac{\partial \overline{U_{i}}}{\partial x_{j}}=-\frac{1}{\rho} \frac{\partial \bar{P}}{\partial x_{i}}+v \frac{\partial^{2} \overline{U_{i}}}{\partial x_{j} \partial x_{j}}-\frac{\partial \overline{u_{i} u_{j}}}{\partial x_{j}}+g_{i}
\end{aligned}
$$

The coordinate systems used in numerical analysis are the space-fixed coordinate system in the main domain and body-fixed coordinate system in the center of gravity of a rigid body. The positive direction of translation and rotation is shown in Fig. 7. Ship motion is assumed to be a rigid body, and only heave and pitch motion were considered, which are the main behaviors of porpoising. The reason why only two motions were considered was to focus on motions during overlapping porpoising and wave motion. Firstly, heave motion translates along z-dimensions, and it is described by Newton's second law as follows:

$$
m \frac{d \overrightarrow{U_{z}}}{d t}=\vec{F}_{z}
$$

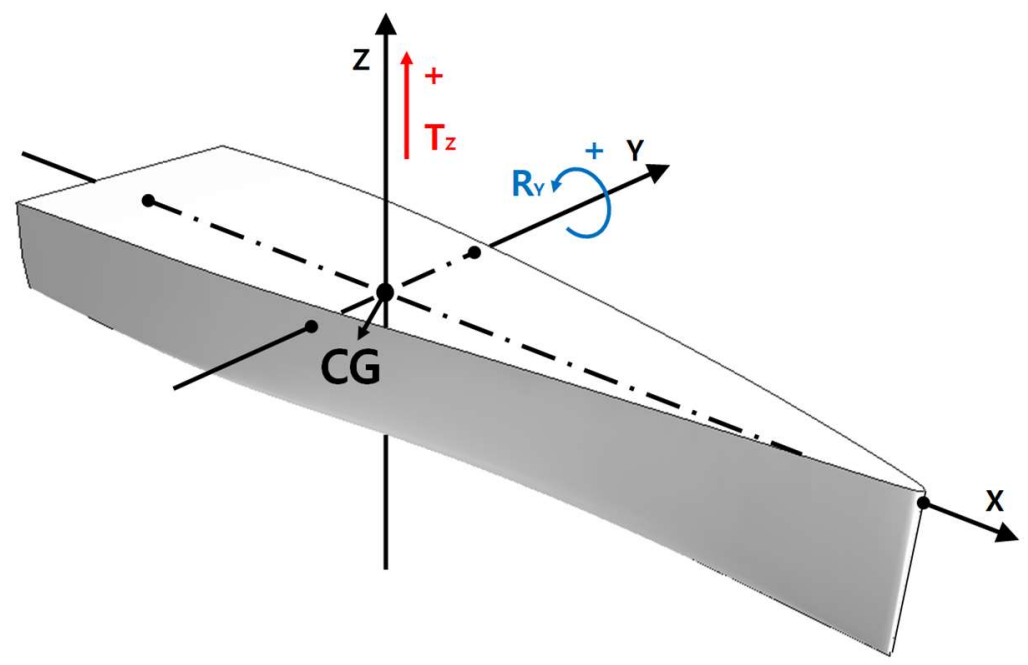

Fig. 7 Definition of 2-DoF in a planing hull

where $\overrightarrow{U_{z}}$ and $\overrightarrow{F_{z}}$ are the velocity in $z$-dimensions and the sum of forces acting on a rigid body in $z$-dimensions. Pitch motion rotates around the y-axes of the body-fixed coordinate system, and it is described by Euler's equations as follows: 


$$
M \frac{d \overrightarrow{\Omega_{y}}}{d t}+\overrightarrow{\Omega_{y}} \times\left(M \cdot \overrightarrow{\Omega_{y}}\right)=\overrightarrow{\tau_{y}}
$$

Where $\overrightarrow{\Omega_{y}}$ and $\overrightarrow{\tau_{y}}$ are the angular velocity and resultant torque acting on a rigid body around $y$-axes of the bodyfixed coordinate system.

In case of the numerical methods, the commercial code used in this simulation is STAR-CCM + , the SST $k-\omega$ turbulence model is applied to get advantage from $k-\omega$ in the region of low turbulence and $k-\varepsilon$ to prevent the problem of $k-\omega$ in the inlet-free stream (Menter, 1994), and it is described in Eqs. (7) to (10).

$$
\begin{aligned}
& \frac{\partial k}{\partial t}+\bar{U}_{l} \frac{\partial k}{\partial x_{j}}=\frac{\partial}{\partial x_{j}}\left[\left(v+\sigma_{k} v_{t}\right) \frac{\partial k}{\partial x_{j}}\right]+P_{k}-\beta^{*} k \omega \\
& \frac{\partial \omega}{\partial t}+\overline{U_{l}} \frac{\partial \omega}{\partial x_{i}}=\alpha S^{2}-\beta \omega^{2}+\frac{\partial}{\partial x_{j}}\left[\left(v+\sigma_{\omega^{\prime}} v_{t}\right) \frac{\partial}{\partial}\right]+2\left(1-F_{1}\right) \sigma_{\omega^{2}} \frac{1}{\omega} \frac{\partial k}{\partial x_{i}} \frac{\partial \omega}{\partial x_{i}} \\
& v_{t}=\frac{a_{1} k}{\max \left(a_{1} \omega, S F_{2}\right)}, P_{k}=\min \left(\tau_{i j} \frac{\partial U_{i}}{\partial x_{j}}, 10 \beta^{*} k \omega\right) \\
& \beta^{*}=0.09, a_{1}=0.31
\end{aligned}
$$

Where $S$ is the modulus of the mean strain rate tensor, $F_{1}$ and $F_{2}$ are blending functions, $\sigma_{\omega}$ and $\sigma_{k}$ are inverse turbulent Schmidt numbers, respectively. The spatial discretization of the convective terms and the temporal discretization are chosen with a second-order upwind scheme for transient problems. Velocities and pressures are solved in a segregated method, which implements the SIMPLE algorithm. The second-order backward Euler scheme is applied for temporal discretization. Additionally, the key features of the numerical method except the above are listed in Table 1 .

\subsection{Numerical Validation}

To secure the reliability of numerical analysis for planing craft, validation work was performed by comparing it with existing experimental results. The validation model, warped hull-form 2, was one of the series models developed by Begovic and Bertorello (2012) shown in Fig. 8 and Table 2. The numerical validation procedure was performed from calm water to wave conditions.

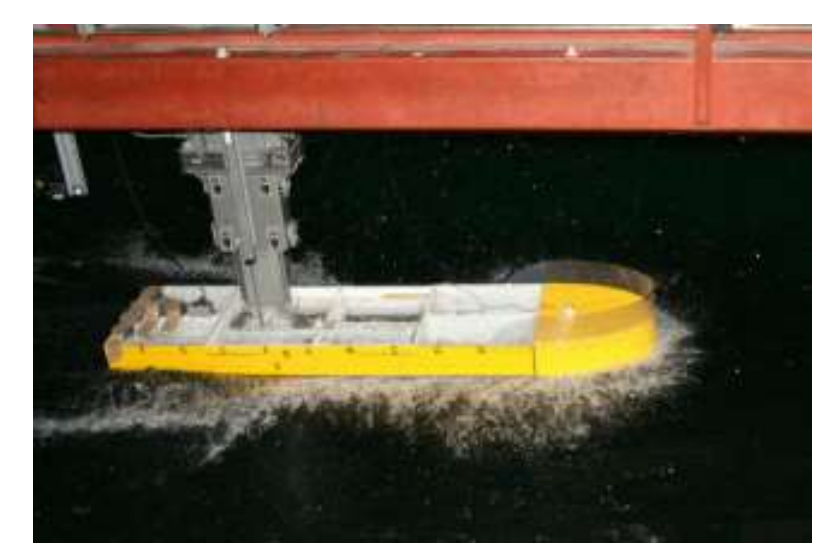

Fig. 8 Warped hull 2 (Begovic and Bertorello (2012) 
In the case of the calm water condition, the resistance component was compared according to the mesh resolution and time-step. Fig. 9 represents the results of the total resistance with the mesh resolution. As the mesh resolution increased, it was confirmed that total resistance gradually converged until the total number of meshes around 1,145,000. Thus, this grid system was applied to next step. Fig. 10 represents the results of the resistance component with the timestep. As the time-step decreased, it was confirmed that the difference between the experiment and numerical simulation also decreased. As a result of comparing pressure and friction resistance, it was confirmed that pressure resistance was constant, but the frictional resistance showed the same trend with the total resistance. The results indicated that the wetted surface area, which related to the friction resistance, also changed with the time-step.

Fig. 11 represents the distribution of the volume fraction under the free surface as the time-step. In general, it was confirmed that numerical air ventilation occurred along the keel. Furthermore, numerical air ventilation extended to the side of the hull as the time-step increased. From these results, we deduce the following points. the wetted surface area was calculated from the area of the volume fraction $=0.5-1$ based on the volume fraction $=0.5$, which is the interface between air and water.

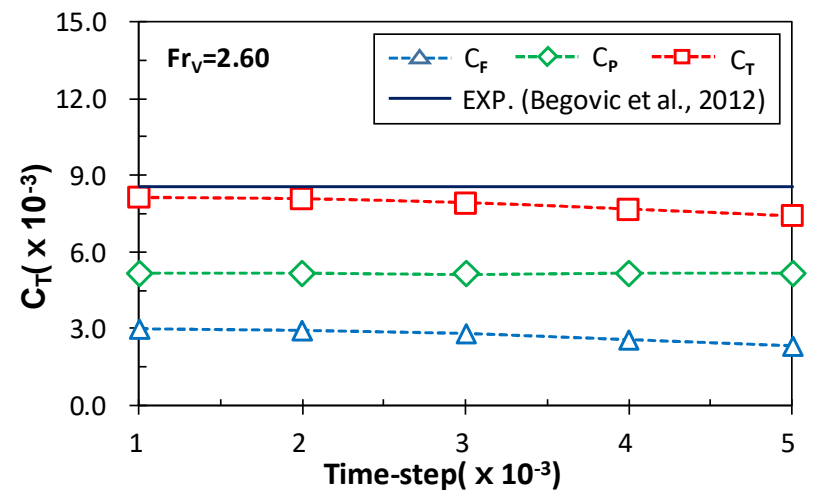

Fig 9 Mesh converge test as total resistance

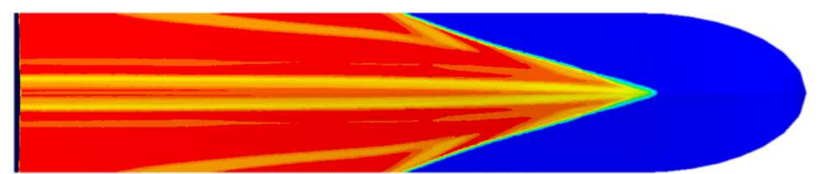

(a) Time-step : 0.001

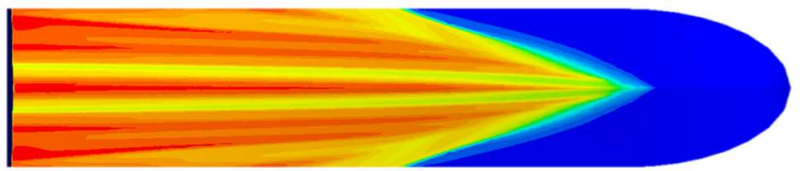

(b) Time-step : 0.003

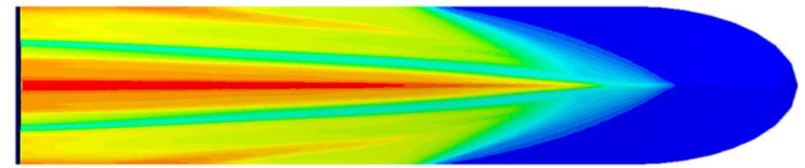

(c) Time-step : 0.005

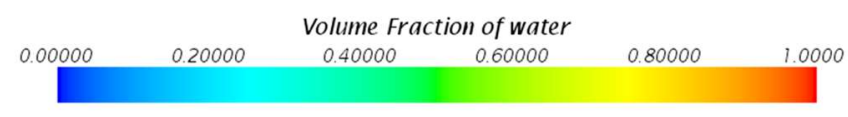

Fig. 11 Distribution of volume fraction of water

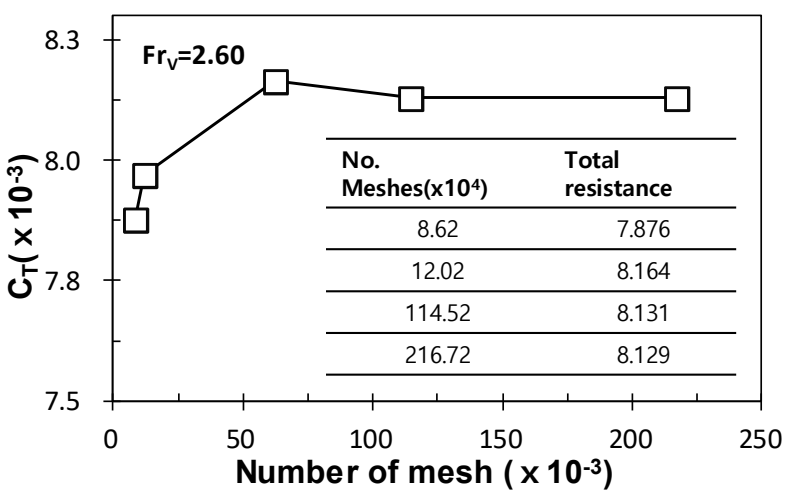

Fig. 10 Time-step test as resistance component
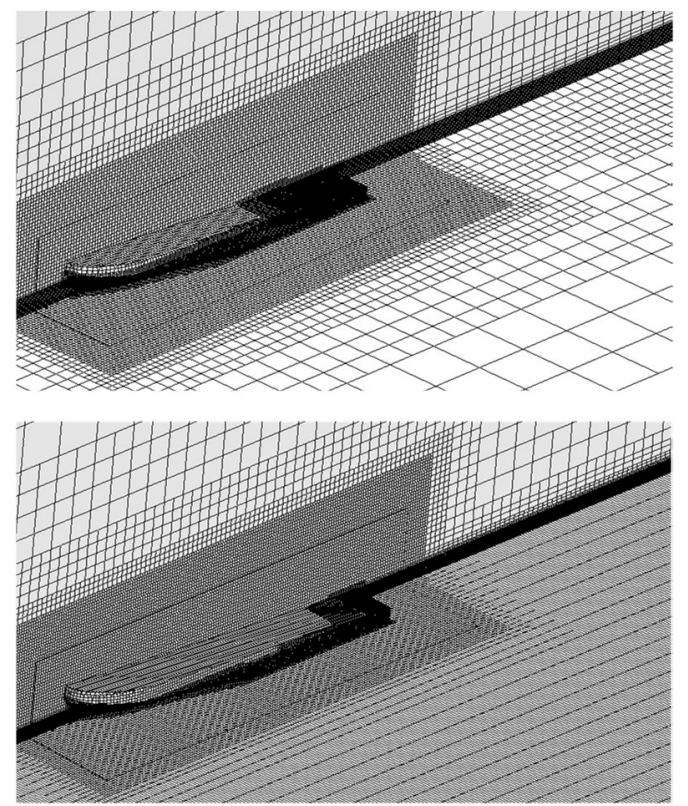

Fig. 12 Refinement on free surface (Up) calm water (Down) wave condition 
Table 1. Key feature of numerical method

\begin{tabular}{cc}
\hline Method & Scheme \\
\hline \hline Wall Treatment & All Y ${ }^{+}$Treatment \\
\hline Spatial Discretization & Cell Centered FVM \\
\hline Multiphase Model & VOF (Volume of Fluid) \\
\hline Free Surface Problem & HRIC Schemes \\
\hline Wave model & 1st-order VOF wave \\
\hline Body motion & Dynamic Fluid-Body Interaction \\
\cline { 2 - 2 } & Overset Grid Method \\
\hline
\end{tabular}

Table 2. Properties of warped hull 2

\begin{tabular}{ccc}
\hline Parameter & Model & Unit \\
\hline \hline LoA & 1.900 & $\mathrm{~m}$ \\
\hline $\mathrm{B}$ & 0.424 & $\mathrm{~m}$ \\
\hline $\mathrm{T}$ & 0.110 & $\mathrm{~m}$ \\
\hline$\beta$ & $11.59-30.11$ & $\mathrm{deg}$ \\
\hline$\nabla$ & 32.630 & $\mathrm{~kg}$ \\
\hline$F r_{v}$ & $1.92 / 2.60$ & -
\end{tabular}

However, the numerical air ventilation phenomenon gradually expanded along the surface as the time-step increased, replacing the volume fraction of some of the region, where the value should be 1 , or around $0.5-1$. By calculating the viscosity formula of the VOF model with the Eq. (11), it was confirmed that the reduction of the volume fraction decreased the viscous coefficient of the wetted surface area. In conclusion, this showed decrements of friction resistance. Therefore, the time-step was used at $0.001 \mathrm{~s}$ to minimize numerical air ventilation.

$$
\mu_{\text {total }}=f_{\text {air }} \cdot \mu_{\text {air }}+\left(1-f_{\text {air }}\right) \cdot \mu_{\text {water }}
$$

In the case of the wave conditions, they were based on the regular wave matrix (Begovic et al., 2014) in Table 3, and the grid system was needed to refine on free surface for generating proper waves. Thus, the total number of mesh was changed from 1,145,000 to 2,239,445 as shown in Fig. 12. In addition, Fig. 13 shows the heave and pitch Response Amplitude Operator (RAO) values that compared the experimental and numerical results, where the heave and pitch RAO are determined as

$$
\text { Heave }_{R A O}=\frac{\eta_{3}}{A}, \text { Pitch }_{R A O}=\frac{\eta_{5}}{K A}
$$

Table 3. Regular wave matrix for validation work (Begovic et al., 2014)

\begin{tabular}{ccccccc}
\hline$f(1 / \mathrm{s})$ & $\mathrm{w}(\mathrm{rad} / \mathrm{s})$ & $\mathrm{K}(\mathrm{rad} / \mathrm{m})$ & $\lambda(\mathrm{m})$ & $\lambda / L_{O A}$ & $\mathrm{~A}(\mathrm{~mm})$ & $H / \lambda$ \\
\hline \hline 1.00 & 6.283 & 4.026 & 1.561 & 0.821 & 16 & 0.020 \\
\hline 0.80 & 5.027 & 2.576 & 2.439 & 1.284 & 20 & 0.016 \\
\hline 0.70 & 4.398 & 1.973 & 3.185 & 1.676 & 20 & 0.013 \\
\hline 0.65 & 4.084 & 1.701 & 3.694 & 1.944 & 32 & 0.017 \\
\hline 0.55 & 3.456 & 1.218 & 5.160 & 2.716 & 35 & 0.014 \\
\hline 0.50 & 3.142 & 1.006 & 6.243 & 3.286 & 35 & 0.011 \\
\hline 0.45 & 2.827 & 0.815 & 7.708 & 4.057 & 45 & 0.012 \\
\hline 0.40 & 2.513 & 0.644 & 9.755 & 5.134 & 45 & 0.009 \\
\hline
\end{tabular}

The numerical and experimental results show good agreement, while there was overestimation around $\lambda / \mathrm{L}_{\mathrm{OA}}<2.3$. One of the reasons considered was that the number of meshes in the vertical direction near the wave region was not enough to generate regular waves while there were enough meshes in the case of regular waves from $\lambda / \mathrm{L}_{\mathrm{OA}}>2.3$. Thus, in further research, refining the mesh in the vertical direction should be considered to increase the accuracy of numerical simulation. 


\subsection{Description of Numerical Model}

In Fig. 14, the model is illustrated, and the properties of the model are shown in Table 4. In the case of the regular wave matrix, $\lambda / \mathrm{L}_{\mathrm{OA}}$ ranged from 0.5 to 6.0 based on that of Begovic et al. (2014), and wave steepness was fixed at 0.025 , as shown in Table 5 .

The computational domain and boundary conditions are illustrated in Fig. 15. The size of the computational domain is expressed by the overall length of the hull $\left(\mathrm{L}_{\mathrm{OA}}\right)$. These dimensions are based on the minimum recommendations of International Towing Tank Conference (ITTC, 2011). This was supplemented by modifying the side plate to the Inlet condition because the wave tended to dissipate during outlet process when the symmetry condition was set on the side plate. Based on the validated grid system, it was necessary to adjust the size of the overset domain and refinement region of the main domain for fitting into the wave-piercing planing hull form. Finally, both parts of the mesh were constructed using the trimmed mesh type, and the total number of meshes was adjusted to around 1,420,000. Each simulation was performed using 10 to 24 cores of local workstations, and computation time took around 170 hours for each case. In Fig. 16 , the detailed structure of the mesh is illustrated, and the mesh density was focused on certain regions of the domain to capture the important flow phenomena around the ship hull.
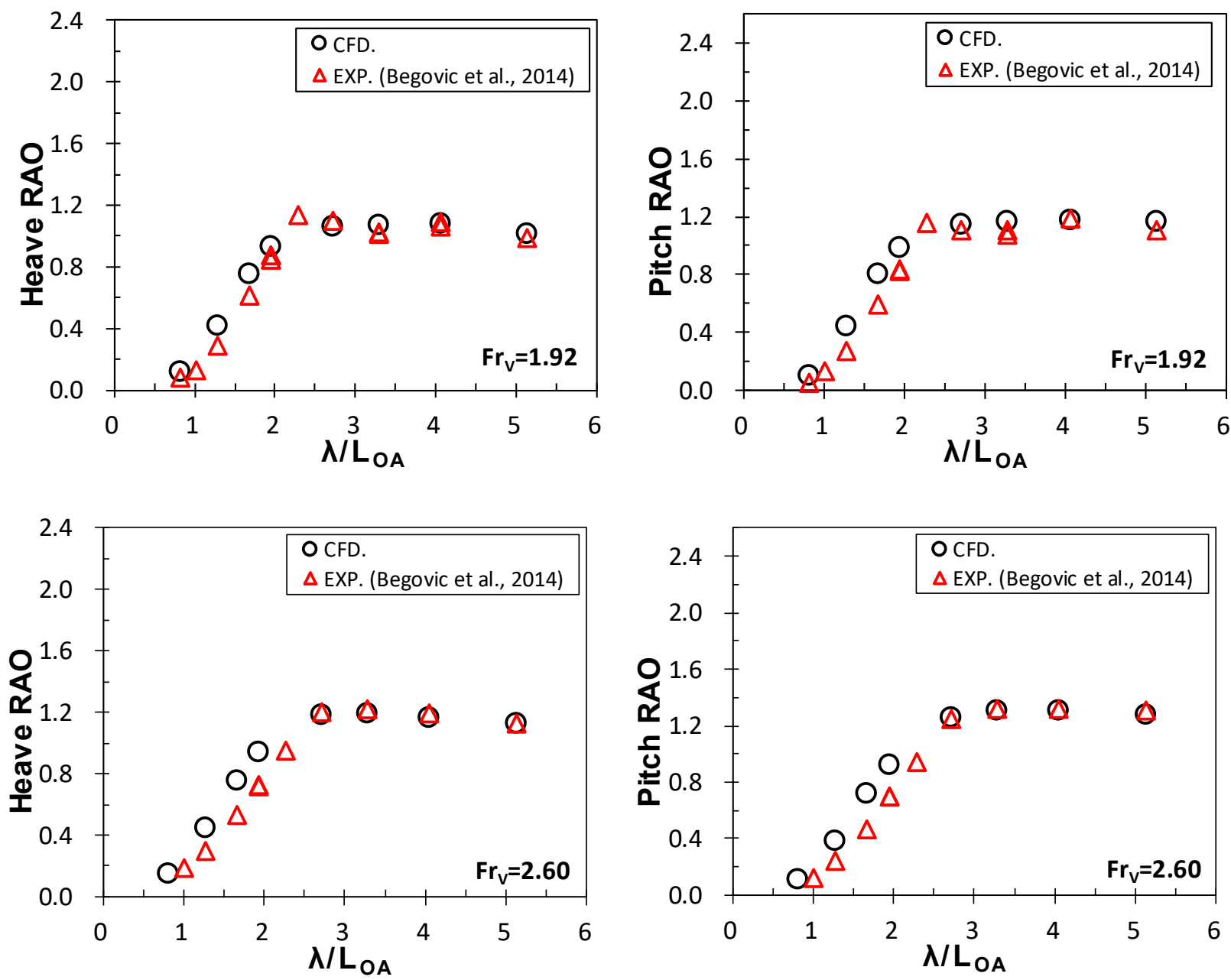

Fig 13. Validation results of heave and pitch RAO 


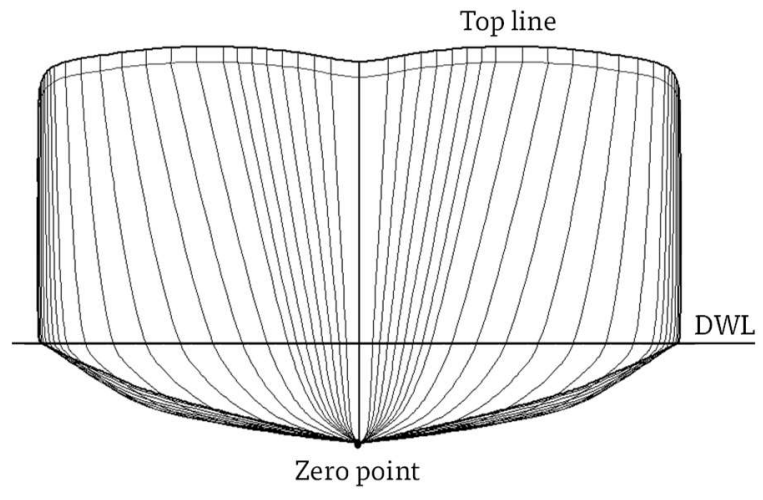

※WL : Design Water Line

Fig 14. Body plan of WPPH (Kim et al., 2017a)

Table 4. Properties of WPPH

\begin{tabular}{|c|c|c|c|}
\hline Parameter & Parent Hull & Model & Unit \\
\hline Scale & 11.429 & 1 & - \\
\hline $\mathrm{LOA}$ & 8.000 & 0.700 & $\mathrm{~m}$ \\
\hline B & 2.3 & 0.201 & $\mathrm{~m}$ \\
\hline $\mathrm{T}$ & 0.326 & 0.028 & $\mathrm{~m}$ \\
\hline LCG & 2.648 & 0.272 & $\mathrm{~m}$ \\
\hline VCG & 0.688 & 0.048 & $\mathrm{~m}$ \\
\hline $\begin{array}{c}\text { Wetted Surface } \\
\text { Area } \\
\end{array}$ & 12.619 & 0.096 & $\mathrm{~m}^{2}$ \\
\hline$F r_{v}$ & \multicolumn{2}{|c|}{4.31} & - \\
\hline$\nabla$ & 2.286 & $1.531 \times 10-3$ & Ton \\
\hline
\end{tabular}

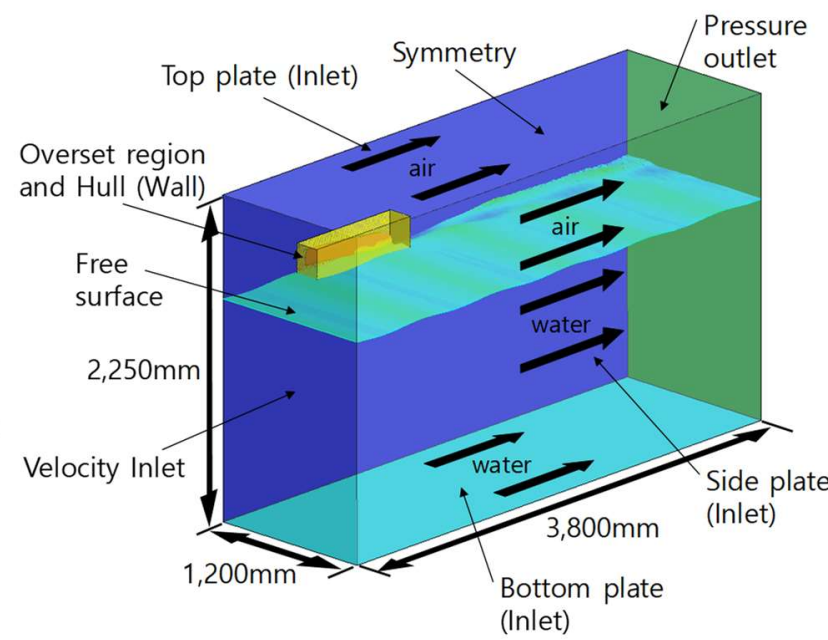

Fig 15. Computational domain / boundary conditions

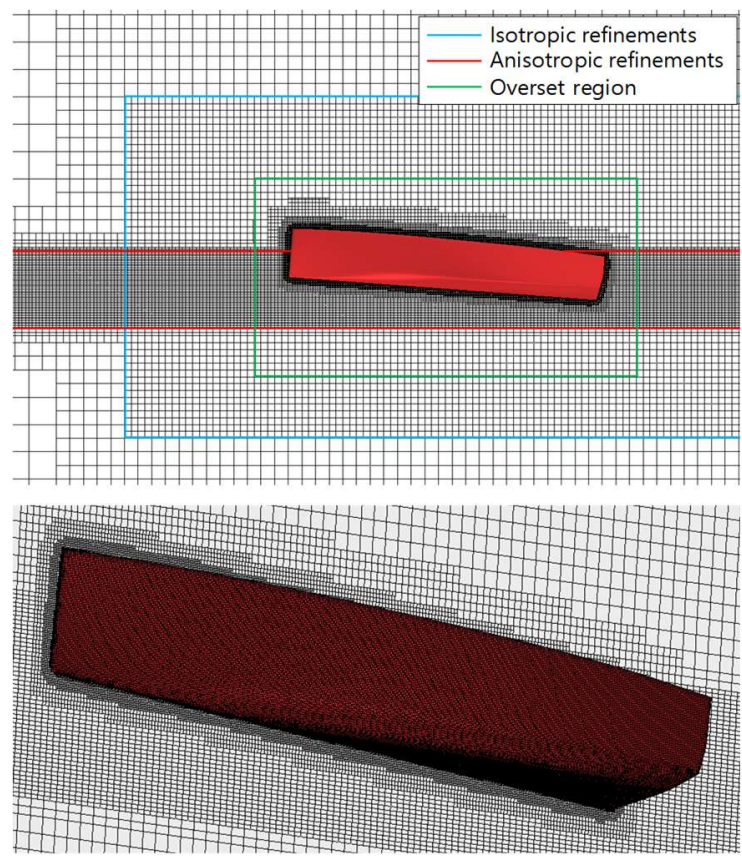

Fig 16. Structure of mesh around hull

Table 5. Regular wave matrix for numerical model

\begin{tabular}{cccccccc}
\hline$f(1 / \mathrm{s})$ & $\mathrm{w}(\mathrm{rad} / \mathrm{s})$ & $\mathrm{K}(\mathrm{rad} / \mathrm{m})$ & $\lambda(\mathrm{m})$ & $\lambda / L_{O A}$ & $\mathrm{H}(\mathrm{mm})$ & $\mathrm{A}(\mathrm{mm})$ & $H / \lambda$ \\
\hline \hline 2.112 & 13.271 & 17.951 & 0.35 & 0.5 & 8.74 & 4.37 \\
\hline 1.493 & 9.384 & 8.975 & 0.70 & 1.0 & 17.50 & 8.75 \\
\hline 1.056 & 6.635 & 4.487 & 1.40 & 2.0 & 35.00 & 17.50 \\
\hline 0.862 & 5.418 & 2.991 & 2.10 & 3.0 & 52.50 & 26.25 & \\
\hline 0.747 & 4.692 & 2.243 & 2.80 & 4.0 & 70.00 & 35.00 \\
\hline 0.668 & 4.196 & 1.795 & 3.50 & 5.0 & 87.50 & 43.75 \\
\hline 0.610 & 3.831 & 1.495 & 4.20 & 6.0 & 105.00 & 52.50 \\
\hline
\end{tabular}




\section{Results and Discussion}

\subsection{Numerical Result for Side Appendages}

In detail, the mesh of the hull surface was refined to prevent the deformation of shape and prism layers were created along the hull to resolve the boundary layer and correct shear stresses. The height of the first cell of the prism layers was set to $y^{+}=34$. In the case of the free surface, it was refined in all directions to prevent the dissipation of waves while only refining free surface for the estimated wake region of the boat in the calm water condition.

Based on the description of the side appendages in Fig. 6 (left), this was applied to the model as shown in Fig. 17. The properties of these appendages were the same as those applied by Kim et al. (2017a). The spray rail was designed to increase in width toward Aft Perpendicular (AP) In the case of the hard-chine, it was designed to extend to the Forward Perpendicular (FP), and the width was designed to be smaller than the spray rail. Because the hard-chine was included in the hull-forms, the hull form deformed more from the bare hull when the width increased. The numerical results were compared for the heave and pitch motion for seakeeping performance and vertical acceleration. Vertical acceleration had a strong correlation with Motion Sickness Incidence (MSI), the parameter for assessing the comfort level of the ship. (Scamardella and Poscopo, 2014)

(a)

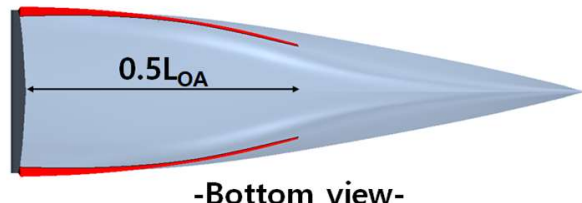

(b)
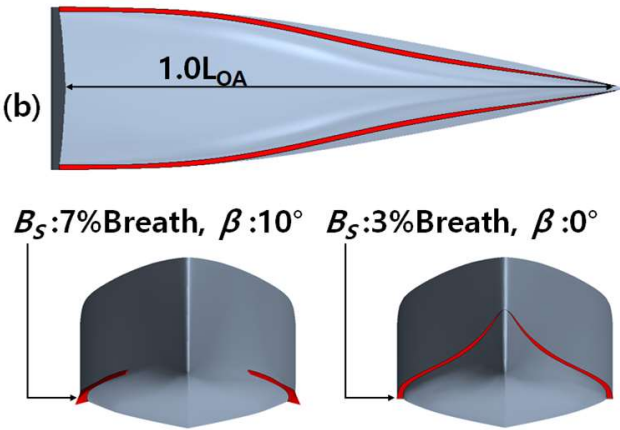

(a) -Front view-

(b)

Fig 17. Side appendages (a) Spray rail (b) Hard-chine

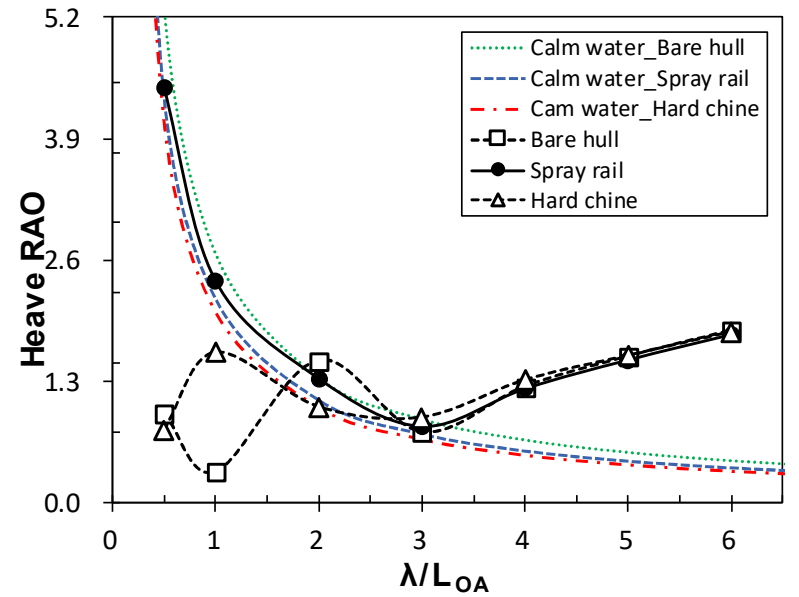

Fig 18. Comparison of Heave RAO on side appendages

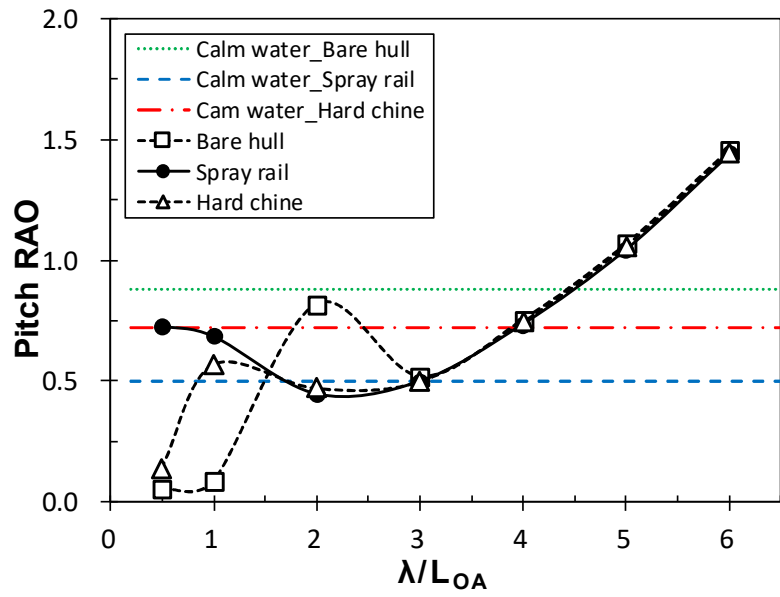

Fig 19. Comparison of Pitch RAO on side appendages 
Figs. 18-19 represent the heave and pitch RAO of the side appendages, and porpoising in calm water converted the RAO value to $\lambda / \mathrm{L}_{\mathrm{OA}}$ to compare them with each other. First, in $\lambda / \mathrm{LOA}_{\mathrm{OA}}>3.0$, heave and pitch RAO showed the same phenomenon. On the other hand, it was confirmed that a remarkable change in motion was shown at $\lambda / \mathrm{L}_{\mathrm{OA}}<3.0$. In addition, it differed depending on the appendage and types of motion.

The heave RAO, spray rail, and hard-chine tended to follow the same tendency as the porpoising while suppressing slightly in calm water. In particular, the spray rail followed the whole of $\lambda / \mathrm{LOA}_{\mathrm{OA}}<3.0$ while the bare-hull only showed in several $\lambda / \mathrm{L}_{\mathrm{OA}}$.

In the case of pitch RAO, it showed a similar tendency to heave RAO. It was clear that porpoising of the bare hull and hard-chine occurred at $\lambda / \mathrm{L}_{\mathrm{OA}}<3.0$ did not over that in calm water, but the spray rail exceeded at $\lambda / \mathrm{L}_{\mathrm{OA}}<1.0$.

From the viewpoint of lift force on the appendages, it is considered that the lift force from the side appendage was periodically generated as waves and enhanced the porpoising while it functioned to generate constant force to stabilize the boat in calm water. The reason why more motion was shown in the case of the spray rail was considered to be that its breadth was wider than that of the hard-chine. Fig. 20 represents the vertical acceleration RAO, which were determined as

$$
\alpha_{C G_{R A O}}=\frac{\alpha_{C G}}{g} \cdot \frac{L_{O A}}{A}
$$

It was confirmed that both values of the spray rail and hard-chine increased at $\lambda / \mathrm{L}_{\mathrm{OA}}<3.0$, and the RAO of the spray rail at $\lambda / \mathrm{LOA}_{\mathrm{OA}}=0.5$ increased continually while that of the hard-chine decreased sharply. Thus, based on Scamardella and Piscopo (2014), it is considered that the comfort level also decreased at $\lambda / \mathrm{L}_{\mathrm{OA}}<3.0$ with the side appendages.

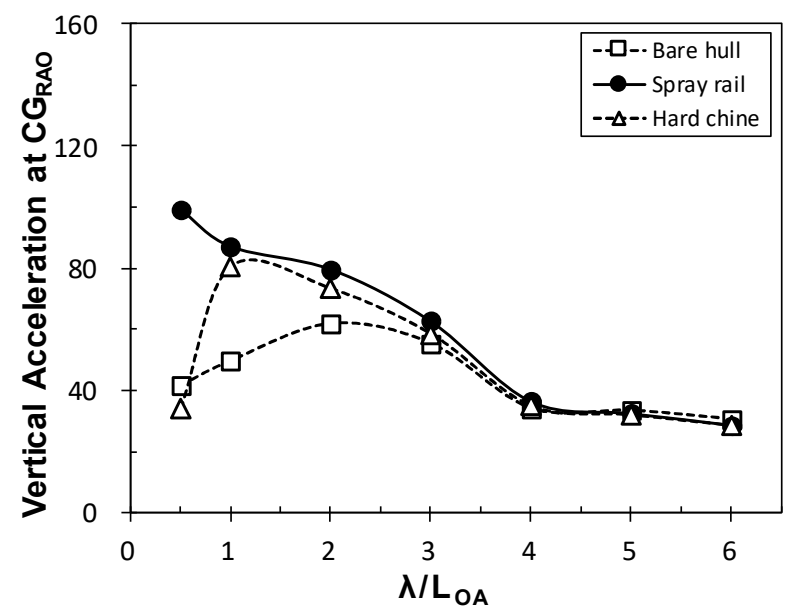

Fig 20. Vertical acceleration RAO of side appendages

\subsection{Numerical Result for Stern Appendages}

Before applying the performance of the stern appendages, a side appendage was selected for independent evaluation from the spray. Therefore, based on the model that applied the hard-chine, the stern appendages were compared and shown in Fig. 21, detailed view from the description in Fig. 6 (right). Between the two types, it was expected that the trim wedge would generate more bow-down moment than the trim tab type because of the angle of the appendages. 
(a)

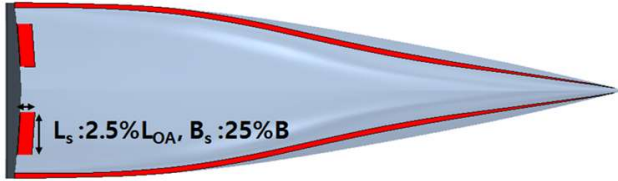

-Bottom view-

(b)
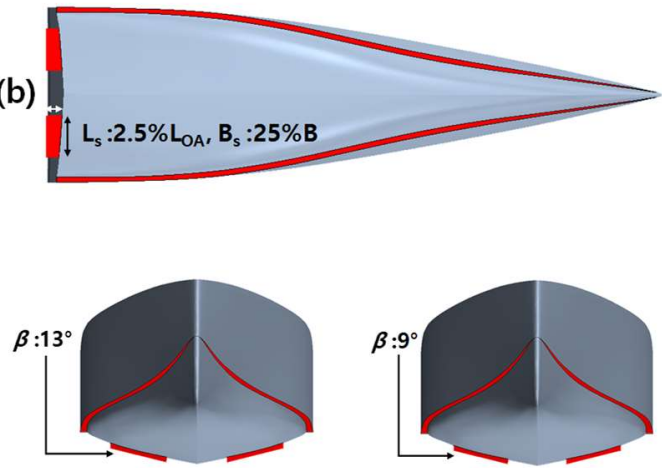

(a) -Front view-

(b)

Fig 21. Stern appendages (a) Trim-wedge (b) Trim-tab

Figs. 22-23 represent the heave and pitch RAO of the stern appendages. It was confirmed that the heave and pitch RAO due to porpoising in $\lambda / \mathrm{L}_{\mathrm{OA}}<3.0$ were suppressed. On the other hand, different features of the stern appendages were shown in $\lambda / \mathrm{LOA}_{\mathrm{OA}}>3.0$. The heave RAO with the stern appendages tended to maintain a constant level. In detail, this trim wedge trend started from $\lambda / \mathrm{L}_{\mathrm{OA}}>4.0$ while that of the trim tab started from $\lambda / \mathrm{L}_{\mathrm{OA}}>5.0$.

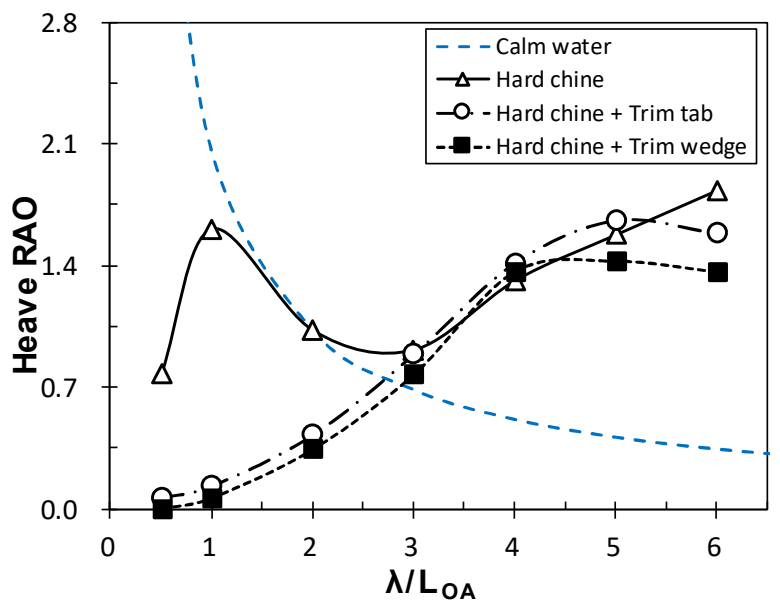

Fig 22. Comparison of Heave RAO on stern appendages

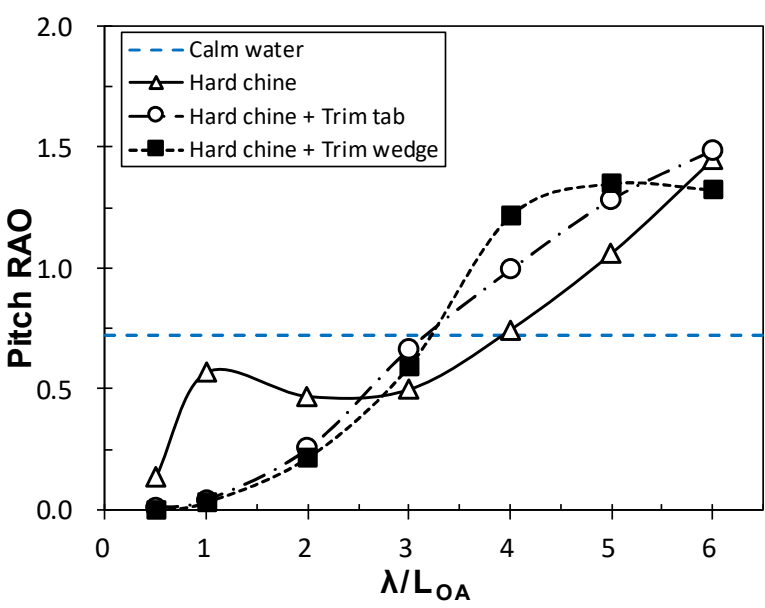

Fig 23. Comparison of Pitch RAO on stern appendages

The pitch RAO of the trim wedge also showed a constant trend, like the heave RAO, while the trim tab showed a linear increment. However, the pitch RAO significantly increased, and the increments of the trim tab and wedge were $10-25 \%$ and $33-38 \%$, respectively. Therefore, it was considered that applying stern appendages could decrease heave RAO but increase pitch RAO. 

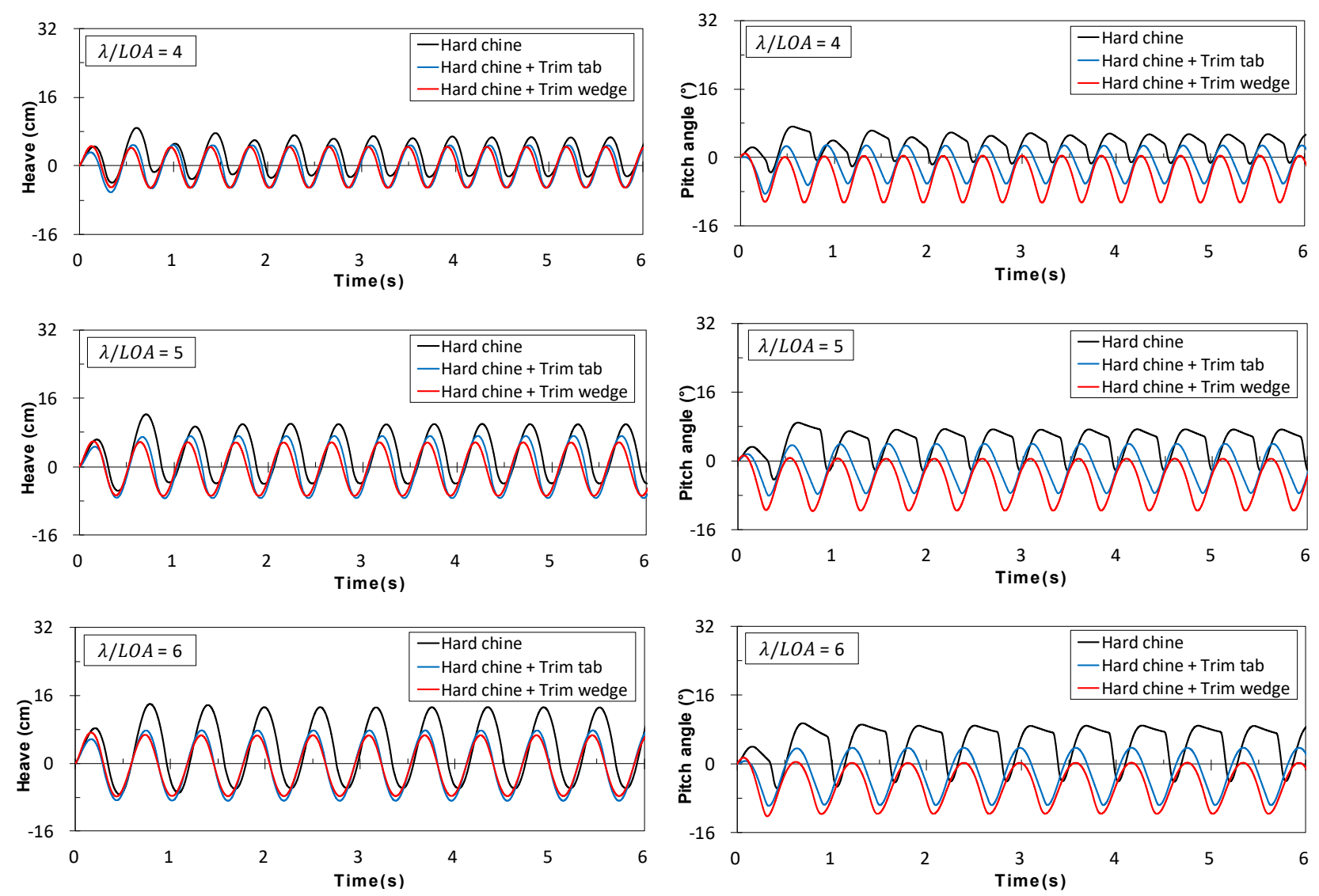

Fig 24. Comparison of time-domain heave motion

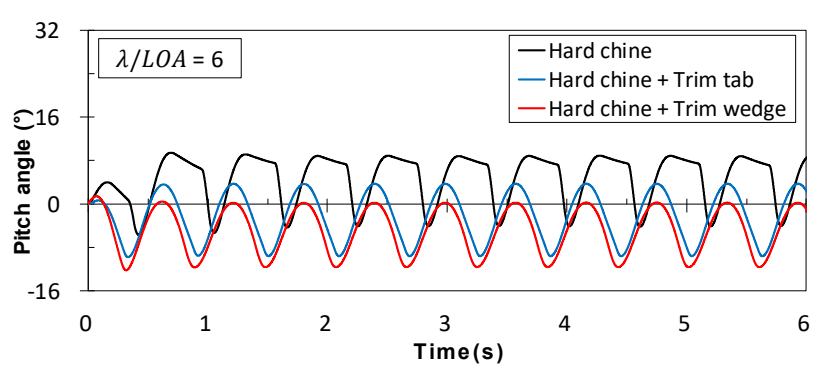

Fig 25. Comparison of time-domain pitch motion

The reason why different features were shown can be explained with Figs. 24-25, which are the heave and pitch angles by the time-domain at $\lambda / \mathrm{L}_{\mathrm{OA}}=4-6$. First, the scope of the two motions shifted down due to the bow-down moment. In the pitch angles, the linear changes from the peak to negative direction, which is considered as the gliding mode, disappeared. Furthermore, the growth of amplitude was also different in each case. Without stern appendages, the growth of amplitude changed from up and down. While applying trim-tab, the amplitude of motion extended to down dominantly. Last, the model that applied the trim-wedge showed the same amplitude and location of motion.

This means the bow-down moment, which was more than a specific amount, sustained the pitch motions. In the heave motion, it also showed similar features, and the increments of amplitude in the upper direction were suppressed. Thus, this trim wedge trend can explain why the RAO of the trim wedge was constant in $\lambda / \mathrm{LOA}_{\mathrm{OA}}>5.0$.

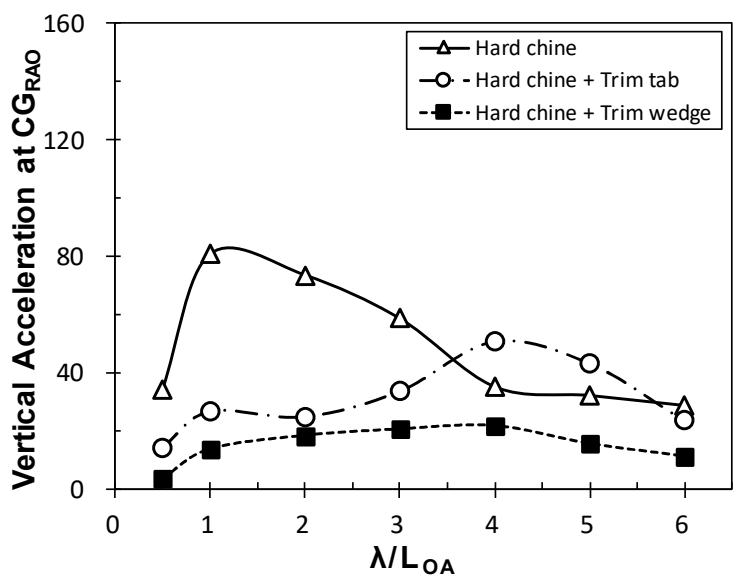

Fig 26. Vertical acceleration RAO of stern appendages 
Fig. 26 represents the vertical acceleration RAO of the stern appendages. First, by suppressing the porpoising in $\lambda / \mathrm{LOA}_{\mathrm{OA}}<3.0$, vertical acceleration also significantly decreased. Second, even if the pitch RAO increased at $\lambda / \mathrm{L}_{\mathrm{OA}}=4.0$ and 5.0 when applying the trim wedge, the vertical acceleration did not increase so much, while that of the trim tab significantly increased. These characteristics of vertical acceleration showed a similar trend to heave RAO and motion, which means that vertical acceleration was related to heave motion. Thus, better performance was shown when applying trim wedge than others.

\section{Conclusions}

In this study, the hydrodynamic characteristics of a wave-piercing planing craft overlapping with porpoising and the wave condition were investigated through a numerical simulation. The motion was divided into heave and pitch motion. The main conclusions of this study are as follows.

In the validation stage, numerical air ventilation was detected under the wetted surface area. This phenomenon was related to the courant number and aspect ratio of the mesh, so it was necessary to study the numerical method to suppress numerical air ventilation or the technique of empirically controlling the mesh and time-step. In addition, numerical simulation was considered only two degree of freedom, but it is necessary to study effect of instability motion to other motion like roll in further research.

In the case of side appendages, it was shown that there were different features for the type of motion. In heave motion, the spray rail was not effective for suppressing porpoising in waves at $\lambda / \mathrm{L}_{\mathrm{OA}}<2$, while the bare hull and hardchine were suppressed somewhat at $\lambda / \mathrm{L}_{\mathrm{OA}}<2$. In pitch motion, for each type of appendage, including the bare hull, there was a different resonance point at $\lambda / \mathrm{LOA}_{\mathrm{OA}}<2$.

Thus, based on the result for the side appendages, we applied stern devices to suppress these motions, and the result was much better than with only side appendages. It was confirmed that porpoising was completely suppressed. However, there was an increment in motions at $\lambda / \mathrm{LOA}_{\mathrm{OA}}>3$. In the case of pitch motion, it was considered that the hydrodynamic force from the trim tab caused this phenomenon.

Consequently, depending on the porpoising and wave condition, it is important for designing appendages for the wave-piercing hull-form. For future work, more detailed characteristics at $\lambda / \mathrm{L}_{\mathrm{OA}}<3$ or irregular waves should be considered.

\section{Acknowledgements}

We thank Dr. Dong-Kun Lee (Mokpo National Maritime University) for providing the experimental results of WavePiercing Planing Hull-forms.

\section{References}

Begovic, E. and Bertorello, C., Resistance assessment of Warped Hull-forms. Ocean Eng. Vol.56 (2012) pp.28-42, DOI: 10.1016/j.oceaneng.2012.08.004

Begovic, E., Bertorello, C., Pennino, S., Experimental Seakeeping Assessment of a Warped Planing Hull Model Series. Ocean Eng. 83 (2014) pp.1-15.

Begovic, E., Bertorello, C., Pennino, S., Piscopo, V., Scamardella, A., Statistical Analysis of Planing Hull Motions and Accelerations in Irregular Head Sea. Ocean Eng. 112 (2016) pp.253-264.

Calderon, A., and Hedd, L., Theoretical and Experimental Investigation on Resistance of Transonic Hull, Proceeding of 9th HSMV, Naples (2011) pp.25-27.

Day, J.P. and Haag, R.J., Planing boat porpoising - a study of the critical boundaries for a series of prismatic hulls, Thesis, Webb Institute of Naval Architecture (1952).

Fridsma, G., A Systematic Study of the Rough Water Performance of Planing Boats. Report 1275. Stevens Institute of Technology (1969). 
Fridsma, G., A Systematic Study of the Rough Water Performance of Planing Boats. Irregular Waves - Part 2. Report SIT-DL-71-1495. Stevens Institute of Technology (1971).

F.W.S. Locke, Jr., General Porpoising Tests of Flying-Boat Hull Models, NACA ARR (1943).

International Towing Tank Conference, 26th ITTC Specialist Committee on CFD in Marine Hydrodynamics. Practical Guidelines for Ship CFD Simulations, Technical report 7.5-03-02-03. Revision 01 (2011).

Jeong, U. C., Lee, D. K. and Jung, K. S., Study of Hull-Form Development of Wave-Piercing-Type High-Speed Planing Boat, Journal of Ocean Engineering and Technology, DOI: 10.5574/KSOE.2016.30.2.069, Vol. 30, No. 2 (2016) pp. 69-74, in Korean.

J.M. Benson and L.J. Lina, The Effect of Deadrise Upon the Low-Angle Type of Porpoising, NACA ARR (1942).

K.S.M. Davidson and F.W.S. Locke, Jr., Some Systematic Model Experiments on the Porpoising Characteristics of Flying Boat Hulls, NACA ARR (1943).

Katayama, T., Mechanism of Porpoising Instabilities for High-Speed Planing Craft. In: Proceedings of Sixth ISOPE Pacific/Asia Offshore Mechanics Symposium, Vladivostok, Russia, September 12-16 (2004) pp.171-178.

Keuning, J.A., Pinkster, J., Optimization of the seakeeping behavior of a fast monohull. In: Proceedings of Fifth International Conference on Fast Sea Transportation (1995) pp.179-193.

Keuning, J.A., Toxopeus, S., \& Pinkster, J., The effect of bow shape on the seakeeping performance of a fast monohull, Proceeding of the 6th International Conference on Fast Sea Transportation (FAST), London (2001) pp.197-212.

Keuning, J. A., Pinkster, J., Van Walree, F., Further Investigations into the Hydrodynamic Performance of the AXE Bow Concept, Proceedings of the $6^{\text {th }}$ Symposium on High Speed Marine Vehicles (HSMV 2002), Castello di baia, Italy (2002)

Kim, S. W., Seo, K.C., Lee, D.K., Lee, G.W., A Numerical Study on Dynamic Instability Motion Control of WavePiercing High-Speed Planing Craft in Calm Water using Side Appendages, Journal of the Korean Society of Marine Environment and Safety Vol. 23 No.3 (2017a) pp.320-329, DOI: 10.7837/kosomes.2017.23.3.320

Kim, S.W., Lee, G.W., Seo, G.C., Lee, D.K. and Park, G.H., Additional Study on Stern Appendages for Suppressing Porpoising of Wave-piercing High-Speed Planing Hull. Annual Autumn Meeting, The Korean Society of Marine Environment \& Safety, 23-24 November, Busan, Korea (2017b) in Korean

Menter, F. R., Two-Equation Eddy-Viscosity Turbulence Models for Engineering Applications, AIAA Journal, Vol. 32, no 8 (1994) pp.1598-1605. DOI: 10.2514/3.12149

Scamardella, A., Piscopo, V., Passenger ship seakeeping optimization by the overall motion sickness incidence. Ocean Eng. Vol.76 (2014) pp.86-97, DOI: 10.1016/j.oceaneng.2013.12.005

Savitsky, D., Hydrodynamic Design of Planing Hulls, Marine Technology, vol. 1, No. 1 (1964) pp. 71-95.

Savitsky, D. and Ward Brown, P., Procedures for hydrodynamic evaluation of planing hulls in smooth and rough water. Mar. Technol. 13 (4) (1976) pp.381-400.

Savitsky, D. and Koebel, J.G., Seakeeping of Hard chine Planing Hulls. Technical Research Bulletin No. R-42, SNAME (1993).

Sottorf W., Systematic Model Researches on the Stability Limits of the DVL Series of Float Design, NACA TM 1254 (1949).

Thompson, A., BOAT, United States Patent, Patent No.:6116180 (1997).

Zarnick, E.E. and Turner, C.R., Rough Water Performance of High Length to Beam Ratio Planing Boats. Report DTNSRDC/SPD-0973-O1 (1981). 